\title{
Barriers and Facilitators to Accessing Mental Healthcare in Canada for Black Youth: A Scoping Review
}

\author{
Tiyondah Fante-Coleman $^{1}\left[\right.$ [ $\cdot$ Fatimah Jackson-Best $^{1}$
}

Received: 2 December 2019 / Accepted: 8 February 2020 / Published online: 27 February 2020

(c) The Author(s) 2020

\begin{abstract}
There is evidence to suggest that Black children and youth in Canada face disproportionate challenges in accessing mental healthcare. Thus, the objective of this scoping review was to map current literature on the barriers and facilitators to care for Black youth in Canada. Both academic articles and gray literature published between January 2005 until May 2019 were reviewed. Six databases were searched for relevant academic articles: CINAHL, PsycINFO, PubMed, EBSCOhost, Social Science Citation Index, and Applied Social Sciences Index \& Abstracts. Gray literature was sourced from community recommendations and Google. Thirty-three (33) sources met the inclusion criteria. Data were coded and analyzed using a thematic analysis framework. Barriers to care for Black youth were identified and occurred at multiple levels of society including systemic (i.e., wait times, poor access to practitioners, geographical challenges and financial barriers to care), practitioner-related (i.e., racism and discrimination from providers, the inability to provide culturally competent care and a lack of organizational support) and personal and community-related barriers (i.e., internalized stigma and stigma from community). Support from family and friends, as well as a good relationship with providers, were noted as facilitators. The findings of this review suggest that Black children and youth face many barriers to accessing the Canadian mental healthcare system despite its purported universality. An increase in funding, expansion of the universal healthcare system to include mental health, and concerted effort on delivering culturally competent care are requisite to facilitate access to care for this population. Further research should focus on Black youth, be rooted in community-based research, and explore intersecting identities in the context of mental illness.
\end{abstract}

Keywords Black youth $\cdot$ Youth $\cdot$ Family $\cdot$ Canada $\cdot$ Mental health

\section{Introduction}

The mental wellbeing of children and youth is becoming a national public health issue in Canada (Archie et al. 2010). Indeed, one out of every five children in Canada who need mental healthcare is unable to access it (Canadian Mental Health Association [CMHA] 2020). Though youth are more likely to be affected by mental illness, they are the least likely to use services to address their mental health needs (MacDonald et al. 2018). Ensuring positive mental health in children and youth is important, as, without intervention,

Tiyondah Fante-Coleman

TFante-Coleman@Blackhealthalliance.ca

Fatimah Jackson-Best

FJackson-Best@Blackhealthalliance.ca

1 Pathways To Care Project, Black Health Alliance, 720

Bathurst Street, Toronto, ON M5S 1Z5, Canada illnesses may not necessarily go away as they grow into adulthood (Lipman and Boyle 2008). Recently, there have been calls from the community highlighting the need to address mental health in Canadian Black children and youth (Patel 2015; Taylor and Richards 2019). Understanding the barriers and facilitators that affect access to mental healthcare for Black children and youth is especially important because they face unique challenges, including racism (Lalonde et al. 2008), higher levels of poverty (Khenti 2013), and social exclusion (Adjei and Minka 2018). Moreover, Black youth who do not access mental health treatment are likely to face difficulty in school, family conflict and increased interaction with the justice system (Planey et al. 2019). Thus, the purpose of this scoping review was to map current literature on the barriers and facilitators to care for Black youth in Canada. 


\section{Canada}

Canada prides itself on its universal healthcare system, and many consider it to be inextricable from Canadians' sense of national identity (Dufresne et al. 2014). Internationally, Canada is often regarded as egalitarian, with a "genuine commitment to comprehensive, accessible health care for all its citizens" (Rodney and Copeland 2009). Indeed, the ability to access care based on need rather than the ability to pay is a national source of pride (Martin et al. 2018). Canada's universal healthcare system is unique in that it is publicly funded, but often privately delivered by independent physicians, clinics or large hospital networks (Martin et al. 2018). Though national sentiment on the healthcare system is positive, recent analysis on healthcare systems in the global north has ranked Canada's healthcare system as 3rd last, primarily due to poor performance concerning equity, healthcare outcomes and access. In particular, reliance on private or out-of-pocket funding for aspects of care not funded by Canada's medicare plan (i.e., prescription drugs, dental care and mental healthcare) impacted affordability and access to care (Grant 2017). Most access to mental healthcare in Canada requires private funding for outpatient services, making it difficult to get this form of care for almost a third of Canadians, among whom racialized people and youth are disproportionately impacted (Martin et al. 2018). Unfortunately, very little is known about the existence of disparities in access to healthcare, including mental health for Black populations in Canada, mainly because race-based data related to health outcomes are not collected (Rodney and Copeland 2009; Nestel 2012).

\section{Mental Health in Black Populations}

Canada is home to one of the most ethnically diverse populations in the world, as $20 \%$ of Canadian residents are foreign-born (Chiu 2017). Black people represent the third-largest population of racialized people in Canada, nearing 3.5\% of the total population (Statistics Canada 2016). As race-based data related to all health outcomes are not collected in Canada, there is very little epidemiological information about the prevalence of mental illness in this population. Though research in Canada is limited, evidence from the United States (US) does shed insight on potential challenges and areas of concern.

A national survey of American adolescents found that $46.8 \%$ experienced some form of mental illness before the age of 18 (Planey et al. 2019; Merikangas et al. 2011). Furthermore, Black youth in the US are more likely to be diagnosed with major depressive disorder (MDD) than white youth and six times more likely to die by suicide due to their depression (Williams et al. 2007). Concerningly, Black youth with MDD were likely to remain untreated. In a national sample of youth with major depression, Black youth in the US were less likely to receive mental healthcare in an outpatient clinic than white youth (Cummings and Druss 2011). Futhermore, racism has implications for the prevalence of mental illness in Black populations. In a review conducted by Paradies (2006) which focused on defining and conceptualizing racism in health research, almost half of the included studies' outcomes focused on mental health. Self-reported racism was also positively correlated with poorer mental health outcomes (Paradies 2006).

\section{Black Youth and Mental Health in Canada}

There remain persistent health disparities among racialized populations in Canada, and Black youth are no exception. Ample research has identified the social and economic challenges that affect the mental health of Black children and youth. Black youth disproportionately access mental healthcare through both forensic and emergency care pathways, which suggests that Black youth are not receiving care unless they are (1) interacting with the justice system or (2) are symptomatic enough to need intensive intervention (Anderson 2015; Anderson et al. 2015). The disproportionate rates of involuntary entryways to care may be due to both the systemic over-policing of this population and a simultaneous delaying of care until symptoms can no longer be managed. There is also evidence to suggest that there is a reliance on the judicial system to access the mental healthcare system in Canada because of how difficult it is to get care through voluntary modes of entry (Finlay et al. 2019). Moreover, Black Canadians may delay or avoid seeking care because of mental illness and mistrust of mental healthcare professionals.

Many activists in the Black community have described mental health and addiction issues as reaching "crisis" levels (Taylor and Richards 2019). Given the challenges Black children and youth face in terms of mental health outcomes, the state of the mental healthcare system is concerning. The current conceptualization of mental healthcare systems is neither designed for young people nor accessible to them (Macdonald et al. 2018). Furthermore, Black youth in Canada need to navigate this insufficient system with the added challenges of discrimination and institutional racism (Arday 2018). Identifying the barriers and facilitators to mental healthcare in Canada is necessary to understand the access needs of Black children and youth in Canada and reduce disparities to access. 


\section{Barriers and Facilitators to Accessing Care}

Despite the lack of relevant research on the access needs of Black populations in Canada, many systematic reviews have explored the barriers and facilitators to mental health in other contexts. Barriers are described by Planey et al. (2019) as "reasons or obstacles that prevent individuals from seeking, obtaining, or completing mental health treatment." Alternatively, facilitators are factors that aid entry to and retention within the mental healthcare system. Researchers have identified personal factors such as self-stigma, difficulty identifying mental illness, and lack of knowledge about available services as barriers to care for American youth (Gulliver et al. 2010) and Canadian immigrants (Thomson et al. 2015). Similar barriers were identified by Planey et al. (2019) in their review of factors that affected access for African American youth. In their review, the personal factors that hindered access to care included a perception that a child was not mentally ill, a pattern of self-reliance and a child's refusal to attend treatment. Internalized and externalized stigma surrounding mental illness contributed to the shame of help-seeking and served as further barriers to care.

Religion can be both a hindrance (Planey et al. 2019) and an enabler to accessing care (Whitley 2012). Dogmatic reliance solely on religion to treat mental illness and a lack of discussion from religious leaders made caregivers and Black youth less likely to seek care. However, when faith communities supported mental health services, youth were more likely to access them. Other facilitators identified in Planey et al.'s (2019) review noted the importance of parent and caregivers' attitudes, capacity, and recognition of their child's mental illness and a supportive social network as important personal determinants of care accessibility.

The characteristics of practitioners also served as key barriers and facilitators to accessing care. A trusting relationship with providers and service staff was considered to be a facilitator. Race, perceived credibility and participants' familiarity with providers also positively impacted access to care (Gulliver et al. 2010; Planey et al. 2019). Moreover, a positive relationship with providers made further treatment more likely (Planey et al. 2019). Especially noteworthy was the way providers engaged and treated their clients as trustworthiness was identified as an important factor that determined youths' careseeking. Cultural rapport and culturally competent care were also noted as important facilitators for African American youth (Planey et al. 2019) and immigrant populations (Thomson et al. 2015). The affordability of mental health treatments, physical accessibility and transportation as well as wait times, appointment availability and timely follow-up were all systemic factors that could help or hinder access to care (Planey et al. 2019).

Some facilitators to care occurred in contexts that were not ideal, including mandated care as a result of involvement with the criminal justice system and involuntary hospitalization. How youth enter care can vary because of access to resources, context, as well as systemic and sociodemographic factors. The process of entering care is often called a "pathway" (Macdonald et al. 2018). These pathways to care reflect the accessibility of the mental healthcare system. In a systematic review of articles that explored pathways to care for youth of all ethnicities, Macdonald et al. (2018) found that Black youth were far more likely to have adverse pathways to care, featuring involvement from law enforcement. One of the studies included in that review found that in the United Kingdom (UK), 25\% of participants had some contact with police (Commander et al. 1999). Moreover, in that sample, police were involved in $60 \%$ of Black participants' entry into the mental healthcare system (Macdonald et al. 2018; Commander et al. 1999). Furthermore, Black patients in this sample were far more likely to be hospitalized against their will (Commander et al. 1999).

\section{Current Study}

Despite the existence of similar research in the United States and the United Kingdom, very little research and programming have been made available and explicitly tailored to the needs of Black youth residing in Canada (Taylor and Richards 2019). Moreover, the barriers and facilitators identified for Black youth in other contexts may not necessarily apply to Canada due to differences in healthcare system delivery (Maticka-Tyndale et al. 2016) and in the ethnic makeup of Canada's Black population (Fante-Coleman et al. 2019). Thus, the purpose of this scoping review is to address the gap in existing research concerning access to mental healthcare for Black children and youth who reside in Canada. In keeping with that goal, the primary research question was: What are the barriers and facilitators to accessing mental health and addictions care for Black youth in Canada?

\section{Methods}

The authors used the protocol for scoping reviews outlined by Arksey and O'Malley (2005) and further expanded upon by Levac, Colquhoun, and O'Brien (2010). For this review, the authors followed the PRISMA reporting guidelines for scoping reviews. Suggestions provided by the Joanna Briggs Institute Reviewers' Manual supplemented methodology and reporting (2015). Levac et al. (2010) outlined six-key steps as necessary for scoping reviews: (1) identifying the research questions, (2) identifying relevant studies, (3) study selection, (4) charting the data, (5) collating, summarizing, and reporting the results and lastly, (6) consultation, which was 
optional. These steps form the basis of the reporting of this article.

\section{Identifying Relevant Studies}

Reviewers met throughout the search process to determine the best course of action. Study selection was an iterative process (Levac et al. 2010). Topics discussed included (1) the purpose of the scoping review, (2) population, context, and outcome, (3) keywords, and (4) databases to be searched. The objective of this review was to identify and map the current state of mental health and addictions care for Black children and youth (population) in Canada. The population referred to Black children and youth (childhood-30 years old) living in Canada. The context was settings where mental healthcare and addictions services are accessed by and offered to Black children and youth and the outcome focused on barriers and facilitators to care. Keywords used were: Black, Youth, Family*, Canada, Mental Health, Substance Use and Addiction, Best Practices, and Community Organizations. The initial focus was solely on mental health and wellbeing. Still, after discussion with project partners, it was decided that it was necessary to also include addictions into the search criteria.

Authors searched for relevant articles in six databases: CINAHL, PsycINFO, PubMed, EBSCOhost, Social Science Citation Index (SSCI) and Applied Social Sciences Index \& Abstracts (ASSIA). The authors had initially intended to use two additional databases: Google scholar and SOCindex but were unable to utilize Boolean phrasing in the former and could not access the latter. Inclusion criteria for the peerreviewed articles were:

(1) Peer-reviewed

(2) Focused on the Canadian context

(3) Original studies using qualitative and quantitative data

(4) Focused on Black youth residing in Canada and mental health namely, the barriers and facilitators to accessing mental healthcare, and best practices for mental healthcare

(5) Published in English

(6) Conducted between 2005 and 2019

Exclusion criteria were:

(1) Gray literature sources, including theses and dissertations

\section{Study Selection}

After conducting an initial search, reviewers determined the number of articles to be inadequate and decided to eliminate two keywords in the database searches: best practices and community organizations. Reviewers adjusted the placement and use of "and" and "or" in the search terms and included those changes above. The final search was conducted on May 14th, 2019. The software reference manager, Mendeley, was used for the initial management of citations and duplicate identification. References were then imported in Covidence, a software designed for systematic review management for further review.

\section{Gray Literature Search}

Gray literature was sourced through a variety of methods. Colleagues familiar with the subject matter and stakeholders in the Pathways to Care project provided some sources. Other gray literature sources were identified on Google by searching the names of well-known mental health organizations that worked with Black communities. Once organizations were identified, the websites of other organizations that they partnered with were also searched for relevant gray literature. If reports were not available to be downloaded, they were requested via e-mail. A Google search was initiated using a combination of the key terms "Black," "youth," "mental health," "addictions," and " Canada." In the search process, Canada was replaced with provinces and cities across Canada for greater specificity.

\section{Charting the Data}

Data were extracted from source material into Microsoft Excel using the following categories: Authors/organization, year of publication, title, objective, province/territory, population demographics (age), population demographics (race), sample size (if applicable), methodology and source type (if applicable), barriers, facilitators, and gaps in research. Authors also charted best practices, the results of which are explored in a subsequent article. Table 1 displays the charted data for peer-reviewed articles and gray literature sources, respectively.

\section{Analysis}

The datasets created in Microsoft Excel were uploaded into Nvivo 12 for further analysis. One author (TFC) coded themes resulting from charted datasets using standard methods for thematic analysis (Braun and Clarke 2006). Both authors reviewed emerging themes and the themes that occurred frequently and which were determined to be salient were selected. 


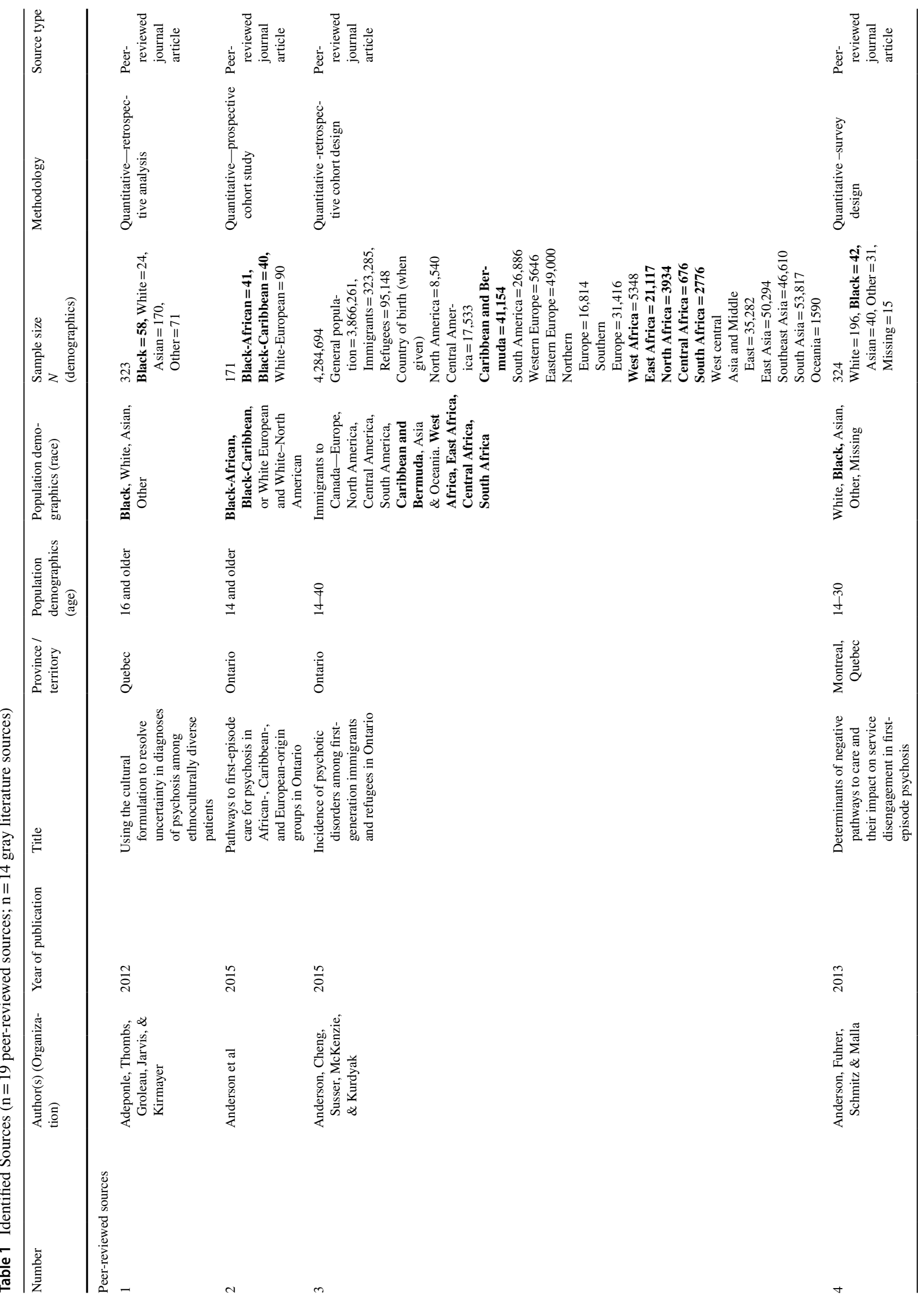




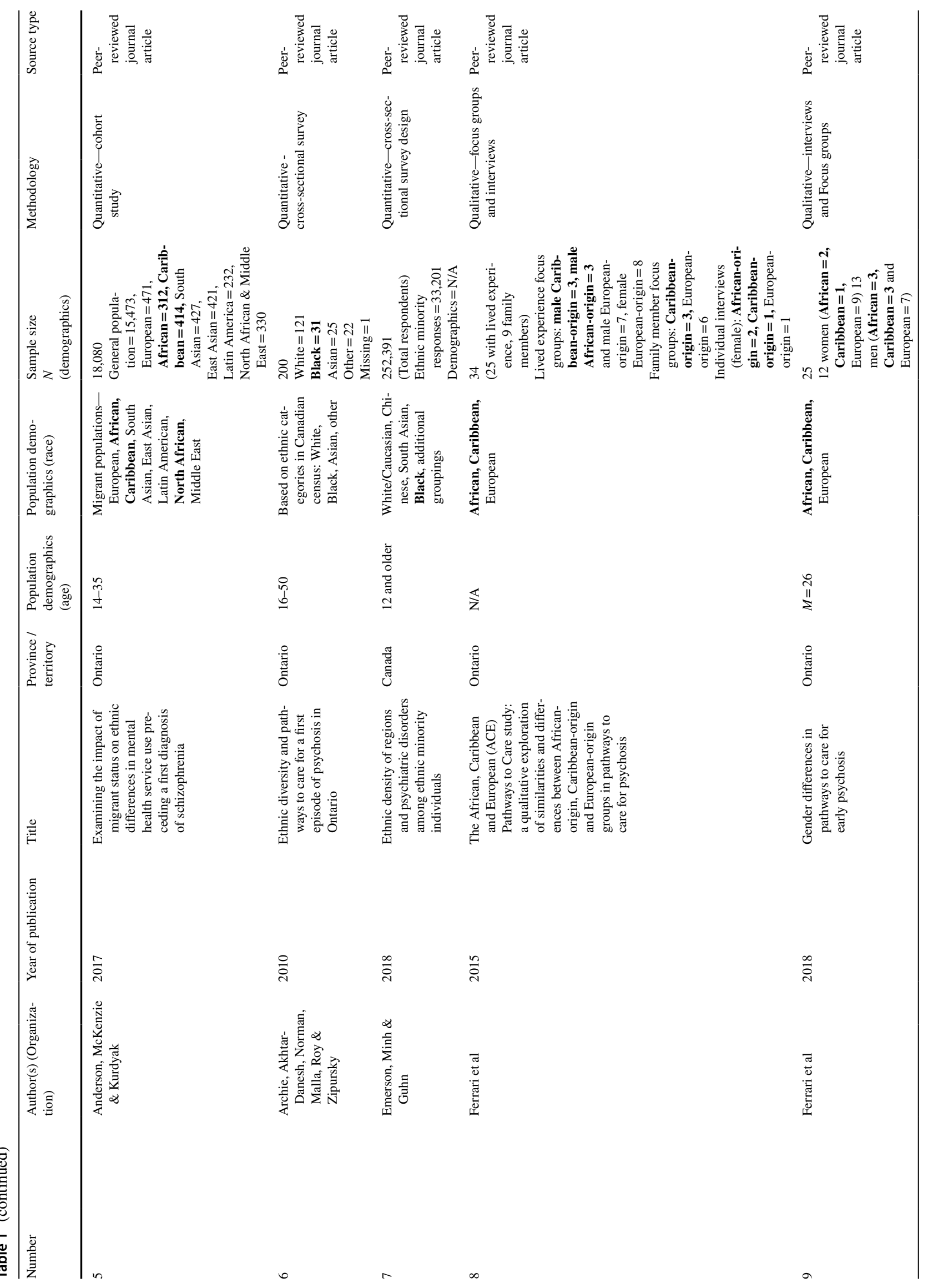




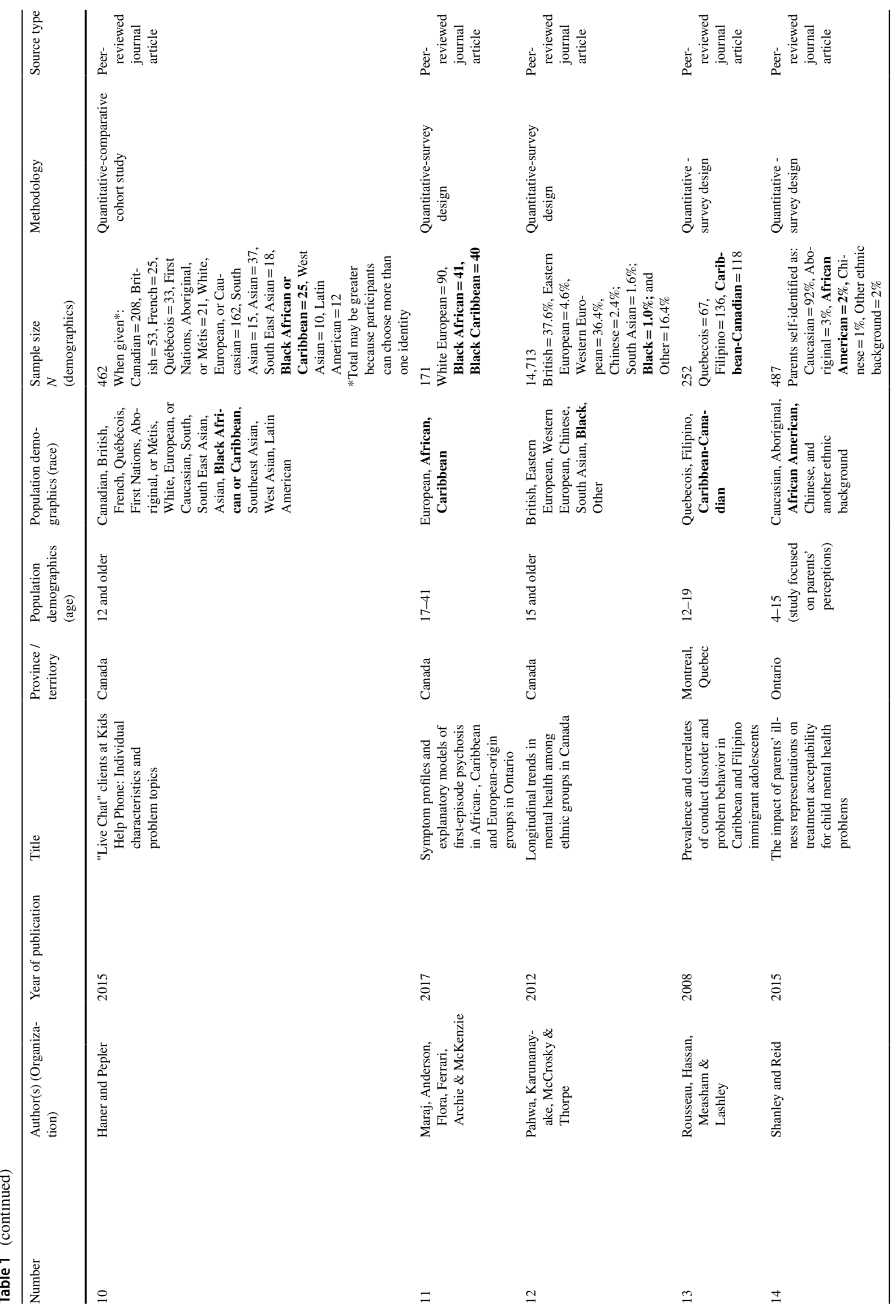




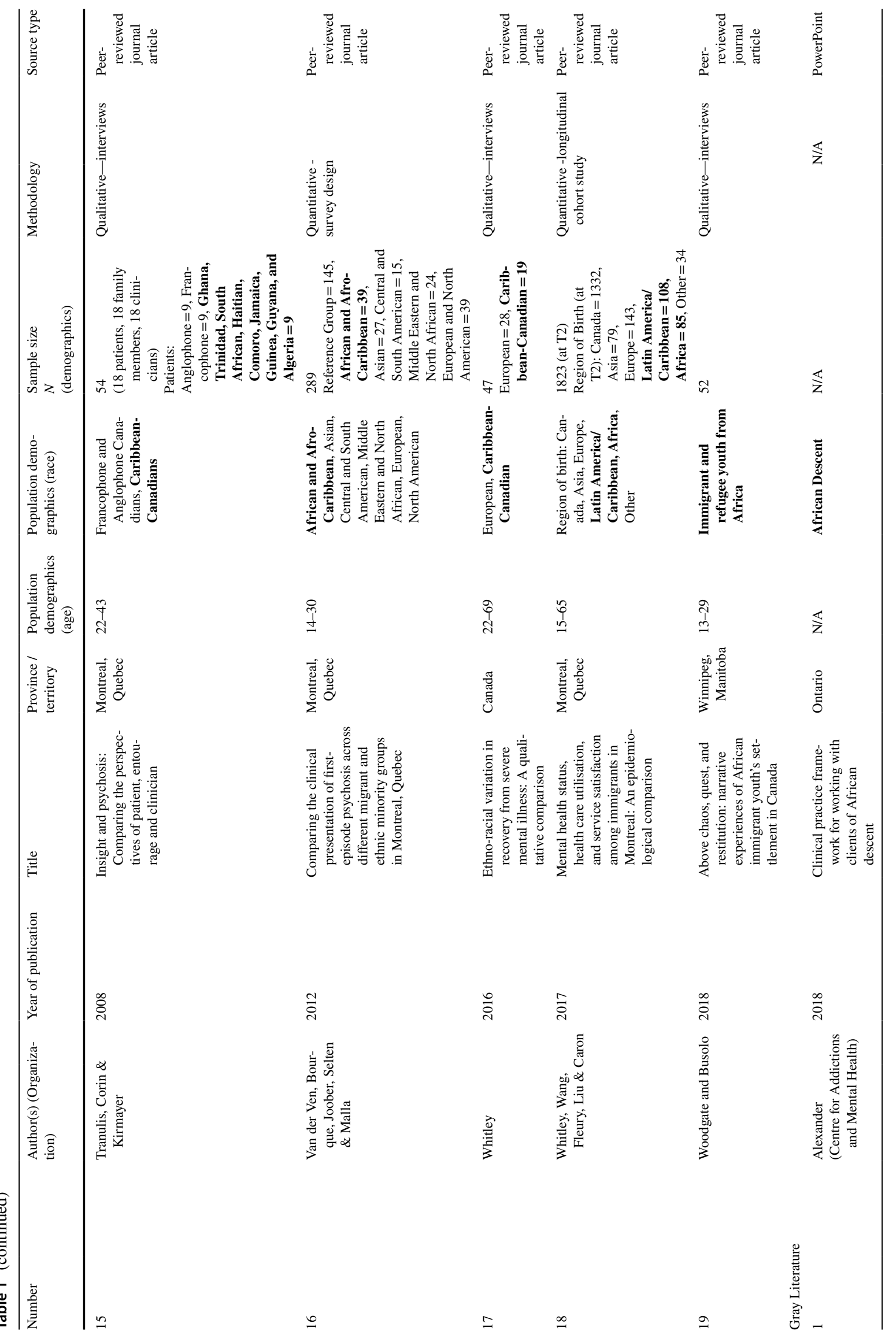




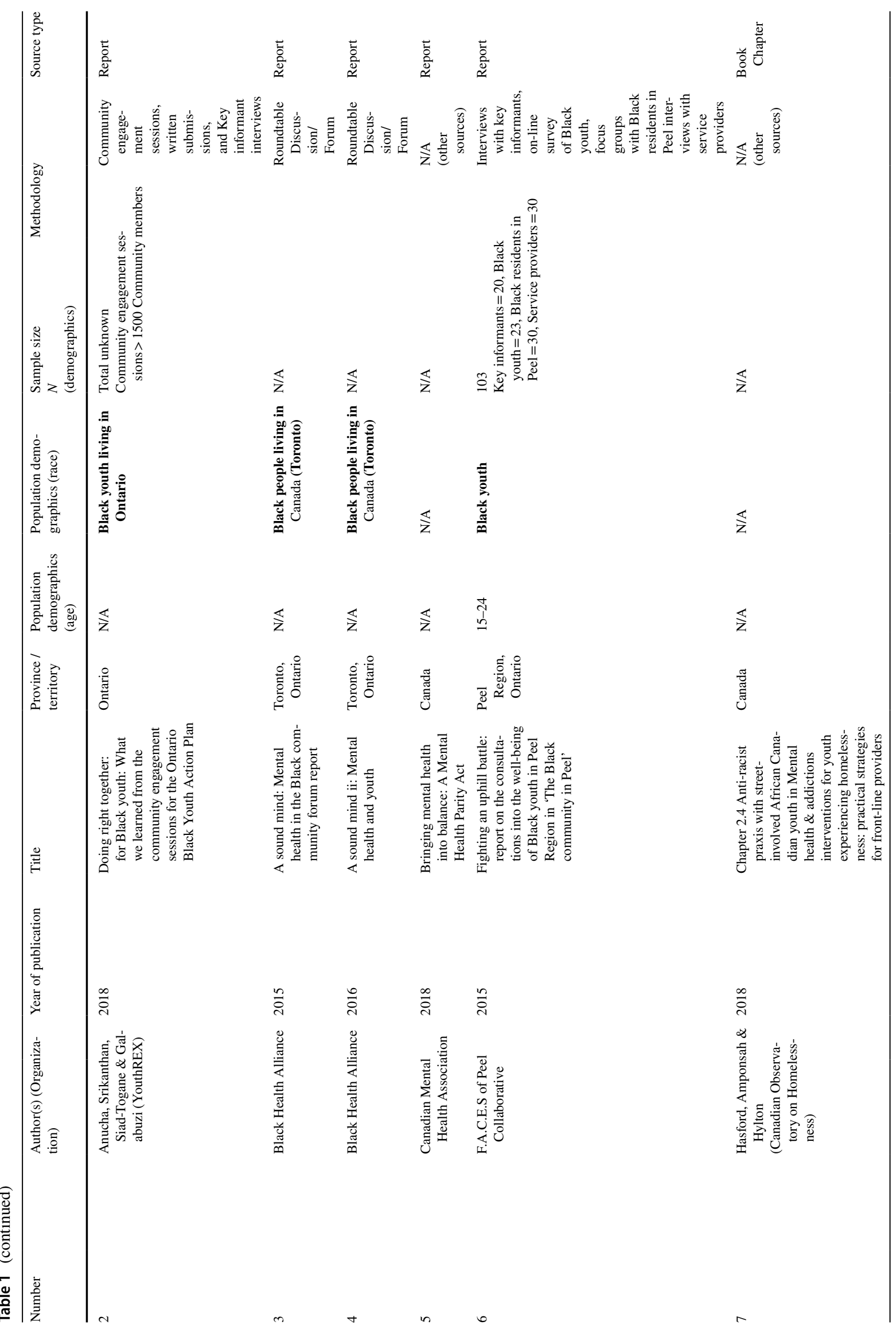




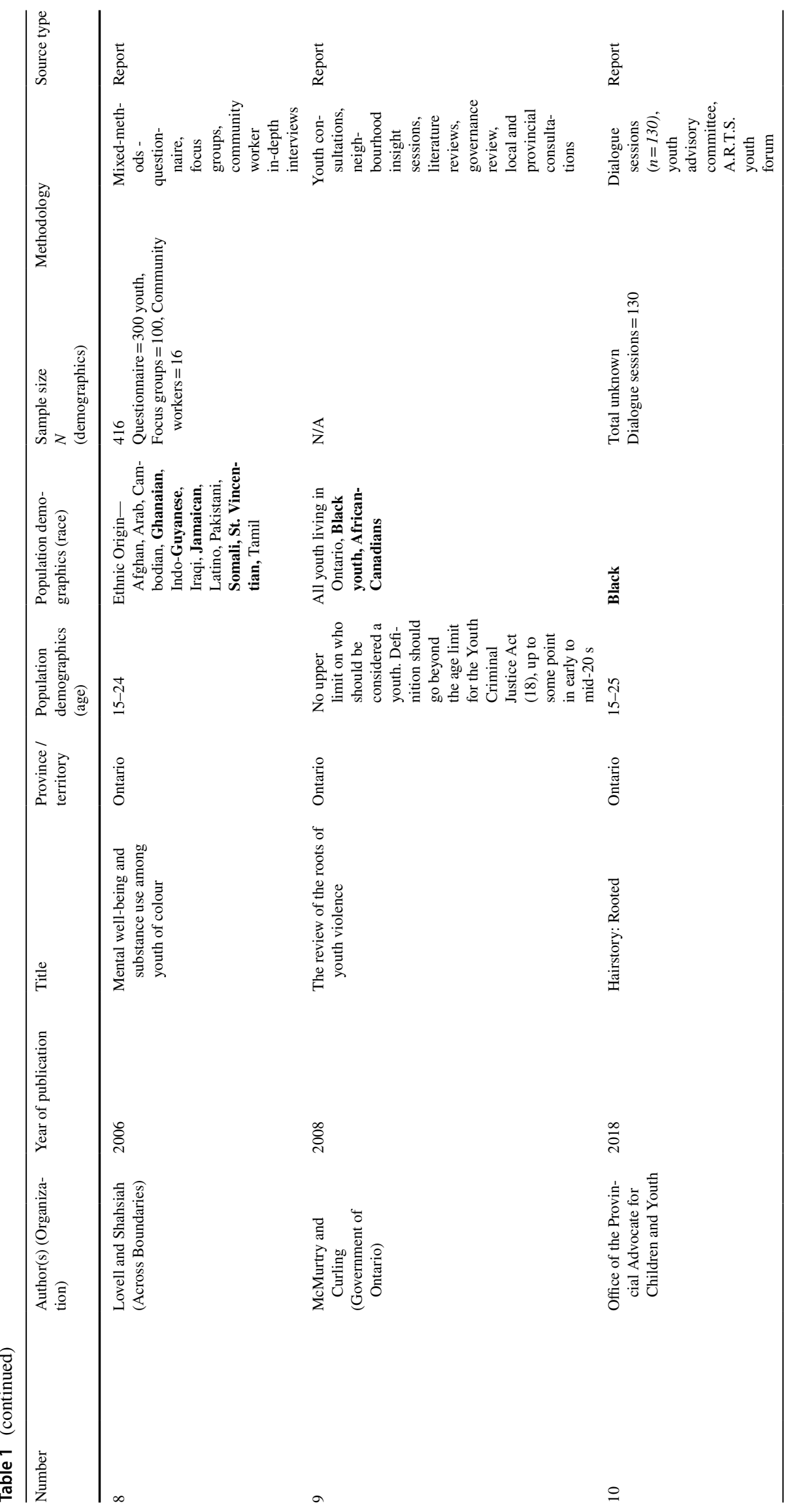




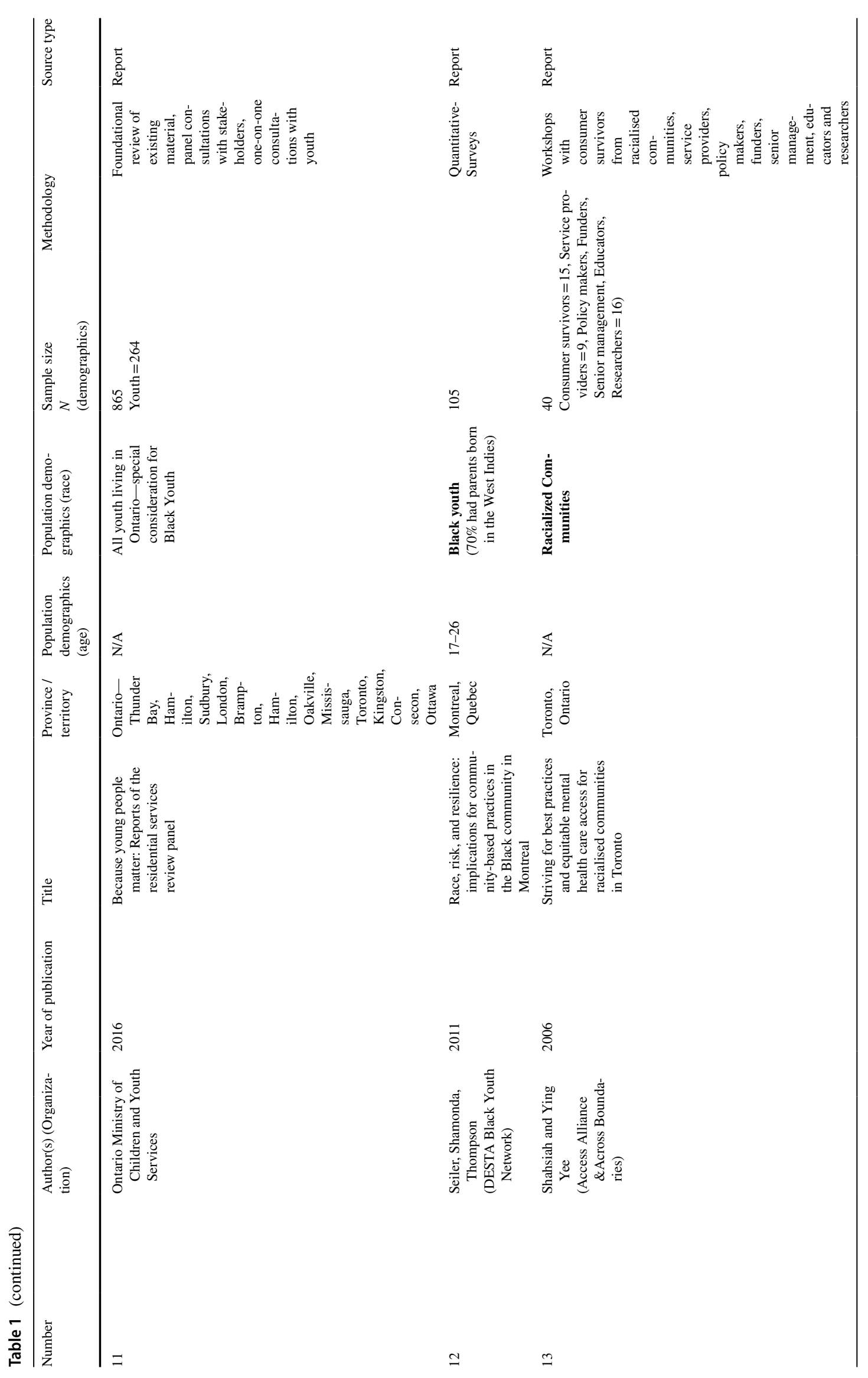




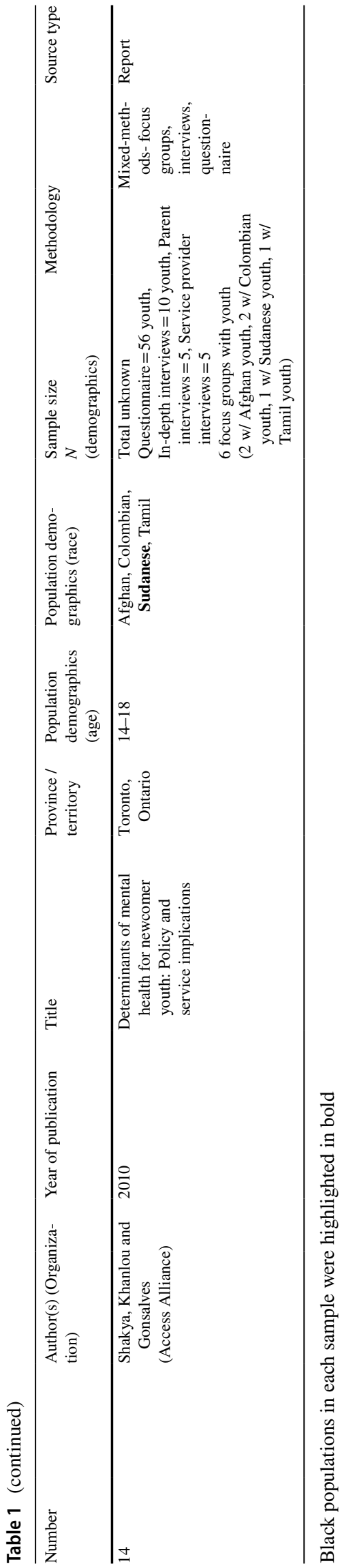

\section{Results}

An initial database search yielded 1700 articles. After the preliminary search, data were screened for duplicates in Mendeley, after which 1176 articles remained for assessment of relevance. Articles were then uploaded into Covidence for further screening. Both authors analyzed the remaining titles and abstracts for adherence to inclusion criteria. Of the 1176 articles reviewed, 1101were discarded, and 75 selected for full-text review. Again, the first and second authors reviewed the full texts independently, and 19 articles were included after review. If there were disagreements, both authors reviewed the article together and determined if it met the inclusion criteria.

Thirty gray literature documents were identified as being potentially relevant to the scoping review based on the title and date of publication. After a full-text review, 14 Gray literature documents met the inclusion criteria. Except for the requirement for peer-review, gray literature sources were assessed with the same criteria used for the peer-reviewed literature. In total, 33 articles and gray literature documents were included in the scoping review (see Fig. 1).

\section{Characteristics of Sources}

The research articles included in this scoping review were mainly concentrated in Ontario and Quebec. More specifically, $36.8 \%$ were conducted in Ontario $(n=7), 26.3 \%$ $(n=5)$ were located in Canada, 31.6\% $(n=6)$ in Quebec $(5$ of which took place in Montreal), and 5.3\% $(n=1)$ in Manitoba. For gray literature, the geographical location was more concentrated. $14.3 \%(n=2)$ of gray literature material was written or conducted with a population that lived in Canada. $78.6 \%(n=11)$ were in Ontario, of which six were in Toronto and surrounding areas, and 7.1\% $(n=1)$ were in Quebec, specifically in Montreal.

In terms of methodology, peer-reviewed studies were mostly quantitative $(73.7 \%, n=14)$, while $26.3 \%(n=5)$ were qualitative in nature. The methodology of gray literature sources was more varied: 3 reports $(21.45 \%)$ used a mixed-methods approach, 50\% $(\mathrm{n}=7)$ used a qualitative approach, including community-forums, panel consultations, engagement sessions, roundtable discussions, and key informant interviews. Two sources (14.3\%) relied on other sourced data to form recommendations, and one source (7.1\%) used a quantitative approach with surveys. The final source was a PowerPoint presentation that did not list a methodology.

The size of research samples in the literature vary. In peer-reviewed articles, they ranged from 25 to 4,284,694 participants. Sample size reporting was not consistent for 


\begin{tabular}{|l|}
\hline \multicolumn{1}{|c|}{ Peer-reviewed search terms: } \\
$(((($ Black OR (African OR Caribbean))) AND (Children \\
OR (juvenile OR adolescent OR teenager OR young \\
people))) AND (Canada OR (Ontario OR British \\
Columbia OR Alberta OR Saskatchewan OR Nova \\
Scotia, New Brunswick OR Manitoba OR Prince Edward \\
Island OR Newfoundland OR Yukon OR Northwest \\
Territories OR Toronto OR Vancouver OR Montreal OR \\
Halifax OR Edmonton OR Calgary OR Saskatoon OR \\
Winnipeg))) AND (Mental Illness OR (emotional health \\
OR healthy mind OR psychiatric health OR mental \\
wellbeing OR mental wellness OR mental hygiene OR \\
psychology OR psychosis OR mental resilience)) \\
\\
Dating from 2005-2019, English and/or French language, \\
identified African, Caribbean and/or Black youth $(>25)$ \\
in population, population resides in Canada, peer- \\
reviewed.
\end{tabular}

Yield from databases searched:

((((Black OR (African OR Caribbean))) AND (Children Columbia OR Alberta OR Saskatchewan OR Nova Scotia, New Brunswick OR Manitoba OR Prince Edward sland OR Newfoundland OR Yukon OR Northwest Halifax OR Edmonton OR Calgary OR Saskatoon OR Winnipeg))) AND (Mental Illness OR (emotional health wellbeing OR mental wellness OR mental hygiene OR Dating from 2005-2019, English and/or French language, in population, population resides in Canada, peerreviewed.

Articles identified in reference list checks: $n=1$

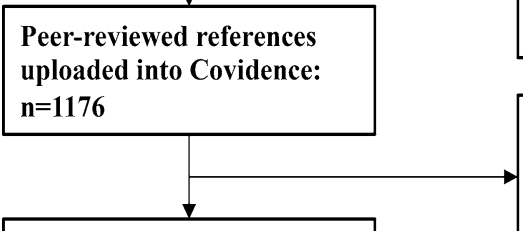

Peer-reviewed references for full-text screening: $\mathrm{n}=75$

Grey literature search terms:

"African" "Caribbean" "Black" "youth" "mental health" "addictions" and "Canada"*

Dating from 2005-2019, English and/or French language, identified African, Caribbean and/or Black youth $(>25)$ in population, population resides in Canada.

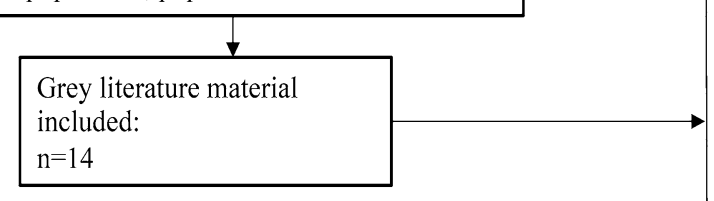

Total included references: $\mathrm{n}=33$ $1^{\text {st }}$ exclusion phase: duplicates $\&$ triplicates excluded by Mendeley: $\mathrm{n}=524$

$2^{\text {nd }}$ exclusion phase: inclusion criteria not met, dissertations, undetected additional duplicates: $\mathrm{n}=1101$

$3^{\text {rd }}$ exclusion phase: inclusion criteria not met: $\mathrm{n}=57$

*: "Canada" was also substituted for major

Canadian cities, "Toronto",

"Montreal", "Halifax" etc.

Fig.1 Presentation of PRISMA map 
gray literature sources, but in sources that did report sample size, the samples ranged from 40 participants to community forums with over 1500 participants. It is important to note that not all gray literature sources secured ethical approval, as academic research and wide dissemination may not have been the intended outcome.

Study participants in gray literature sources who fell under the umbrella category of "African, Caribbean, and Black" were described as "Black," "of African descent," and others were described as belonging to "racialized communities." Descriptions included also characterized their samples by countries of origin where race had to be assumed by the authors, such as "Ghanaian," "St. Vincentian," and "Sudanese" and of "West Indian" descent (a common alternative for Caribbean). Common population descriptors in peerreviewed articles included "African," "African-American," "Caribbean," "Black-African," "Black-Caribbean," "Black." Other descriptions included "Black," as described in the Canadian census, "Caribbean-Canadian," "Afro-Caribbean," "immigrant and refugee populations from Africa," as well as "migrant populations from Africa." Of note, many peerreviewed articles included other populations in addition to "Black" people. Further details are noted in Table 1.

Nine sources mentioned grounding their research in a theory or approach. The most common was an anti-oppressive framework, which was used by four sources (Black Health Alliance 2015; Lovell and Shahsiah 2006; McMurtry and Curling 2008; Seiler et al. 2011). Three sources used an antiracist approach (Hasford et al. 2018; Black Health Alliance 2015; Lovell and Shahsiah 2006). There was overlap in the use of both of the preceding theories likely because they are closely related and often draw from each other. Lastly, the use of socio-cultural theories, which related context to mental illness, was also common (Emerson et al. 2018; Tranulis et al. 2008; Whitley 2016).

\section{Barriers to Mental Healthcare}

\section{Systemic Barriers}

Many of the obstacles to care related to structural problems within the mental healthcare system in Canada. Barriers included wait times to access mental healthcare practitioners, poor access to practitioners (especially Black practitioners), and geographical and financial barriers to care. Lastly, adverse pathways to the mental healthcare system were identified as barriers.

Wait times in the mental healthcare system for Black children and youth were noted as a significant barrier. Anderson et al. (2015) found that Black-Caribbean populations waited on average, 16 months for care, more than twice the wait experienced by white patients, who waited for seven.
Black patients also had referral delays between three and four months (Anderson et al. 2015). One explanation for wait times attributed them to a lack of funding for evidence-based psychological services delivered by psychologists and other mental health professionals (CMHA 2018). Other reasons cited for wait times highlighted a shortage of mental health professionals, including psychiatrists, psychologists, nurses, and social workers (McMurtry and Curling 2008), as well as a poorly defined system of care (Lovell and Shahsiah 2006).

Poor access to mental health professionals often led to inadequate follow-up and poorer mental health outcomes (CMHA 2018). Access to family doctors is often a primary pathway to mental health and addiction services, and $80 \%$ of Canadians rely on them for mental healthcare (CMHA 2018). Still, many Black youth have poor access to family physicians (Anderson et al. 2017). Anderson et al. (2015) identified that only $35 \%$ of Black-Caribbean and $51 \%$ of Black-African participants had access to a family physician in accessing care, compared to $62 \%$ of white participants. Furthermore, family physicians play a prominent role in mental healthcare, but they may be too resource-strapped to meet mental healthcare demands adequately (CMHA 2018). Access to Black mental health professionals was noted to be of particular importance (Office of the Provincial Advocate for Children \& Youth 2018). However, there remains a pronounced lack of available Black professionals in the mental healthcare sector (Shahsiah and Ying Yee 2006).

Sources cited poor access to services for Black children and youth due to geographical barriers (F.A.C.E.S. of Peel Collaborative 2015). There was a dearth of services available to low-income communities, despite the higher prevalence of mental illness within them (F.A.C.E.S. of Peel Collaborative 2015). Lack of knowledge about services also impacted care (F.A.C.E.S. of Peel Collaborative 2015). Citing prior research, the CMHA (2018) suggests that the Canadian universal healthcare system in its current state prioritizes increased psychiatric treatment for those who have higher socioeconomic status and comparatively milder psychiatric disorders. This focus further disadvantaged groups with persistent or severe mental illness.

Financial challenges were frequently noted as a barrier to care (Whitley 2016). Mental health and addiction services in Canada (except for hospital in-patient services) either require payment out-of-pocket or private insurance coverage from "good, stable employment" (CMHA 2018). The need for upfront payments for care may alienate Canadians who are un- or underemployed and cannot afford them. Similarly, medications also pose a financial barrier to care if the client has to pay out of pocket (CMHA 2018). The financial barriers to care may compound access challenges related to race, as disparities exist in accessing clinicians for Black children and youth. White participants were far more 
likely to receive mental healthcare through a psychologist, likely because of their increased access to private insurance (Archie et al. 2010). These challenges may also impact the healing trajectory as financial strain was also noted as a barrier to recovery (Whitley 2016).

Black youth are underrepresented in treatment-oriented voluntary services and overrepresented in imposed services such as correctional facilities and hospitalization (Ontario Ministry of Children and Youth Services 2016). Though access to care in hospitals alleviated financial barriers to care, it is linked to decreased use and dissatisfaction with mental health services. In this review, findings suggest youth were not comfortable accessing hospitals (McMurtry and Curling 2008), which were seen as harmful to mental health (van der Ven et al. 2012) and incompatible with recovery (Whitley 2016).

Hospitalization was also associated with a lack of follow-up. Lovell and Shahsiah (2006) noted that consumer survivors often felt "regret at having sought mental health services in the first place, particularly with regards to psychiatric and hospital-based services." Unfortunately, Black youth were likely to be involuntarily committed (van der Ven et al. 2012) and to first present for treatment at hospitals (Anderson et al. 2017).

In addition to hospitalization as an adverse pathway, Black children and youth are also accessing care through the criminal justice system (Alexander 2018). In a study by Archie et al. (2010), 23\% of Black youth were introduced into mental healthcare treatment by police. Black youth remain untreated for mental illness due to a lack of access to voluntary services (Ontario Ministry of Children and Youth Services 2016), underfunding of services that are culturally responsive (CMHA 2018), and stigma from within the community (Anucha et al. 2017). These untreated mental health issues are then addressed in the criminal justice system (McMurtry and Curling 2008; Office of the Provincial Advocate for Children and Youth 2018). Black youth entering care through the criminal justice system is of concern because it is ill-equipped to address mental illness, which encourages further criminalization (Office of the Provincial Advocate for Children and Youth 2018).

\section{Practitioner Related Barriers to Receiving Care}

Many challenges to receiving care were identified, including racism and discrimination in accessing care, difficulty putting anti-Racism praxis into action, and a lack of organizational support for practitioners.

\section{Racism and Discrimination}

Racism within society at large contributes to the likelihood and severity of mental illness (Anderson et al. 2015) and is an obstacle to gaining access to mental health services (Shahsiah and Ying Yee 2006). Furthermore, racism is historically entrenched in mental health pedagogies (Alexander 2018) and overlaps with the stigma of mental illness to encourage further prejudiced treatment of Black youth seeking care from mental health providers (Lovell and Shahsiah 2006).

\section{Putting Anti-racism Praxis into Action}

Many treatment programs remain Eurocentric in nature (Shahsiah and Ying Yee 2006), fail to provide culturally competent care (Archie et al. 2010), and lack understanding of the complex needs and intersecting oppressions that Black youth encounter (Office of the Provincial Advocate for Children \& Youth 2018). Eurocentric care is problematic as it can reinforce stereotypes (Alexander 2018) and further silence and marginalize clients (Shahsiah and Ying Yee 2006). When Eurocentric and culturally incompetent care forms the basis of practice, the result is ineffective care that often fails to address the realities of Black clients (Shahsiah and Ying Yee 2006).

A lack of cultural understanding can have serious consequences. The consequences identified in this review included improperly diagnosing mental illness (van der Ven et al. 2012), over or under-medicating (Shahsiah and Ying Yee 2006), improperly medicating (Tranulis et al. 2008) and misunderstanding patients' cultural representations of their experiences, which often drew on religious imagery (Tranulis et al. 2008; van der Ven et al. 2012). The experiences of racism, the lack of culturally competent care and the inability to include holistic aspects of mental healthcare (Black Health Alliance 2015; Shahsiah and Ying Yee 2006) often manifested as the alienation of Black consumers and caused further distrust (Office of the Provincial Advocate for Children \& Youth 2018). Moreover, mistrust of the mental healthcare system was cited as a reason for disengagement from mental health services (Hasford et al. 2018). Among immigrant and refugee youth, only $3.8 \%$ discussed seeking mental healthcare, mainly because they did not trust the approaches used (Woodgate and Busolo 2018). Lastly, cultural stigma (Hasford et al. 2018), and marginalizing stigma from healthcare professionals (Ferrari et al. 2015; Shahsiah and Ying Yee 2006) were also cited as barriers to care.

In addition to racism and discrimination impacting access to the mental healthcare system, practitioner challenges related to their organizations also presented as a barrier. When practitioners wanted to provide culturally competent care, they faced constraints related to praxis. Many 
practitioners found that there was a "conceptual gap" (Shahsiah and Ying Yee 2006) between identifying the need for anti-racist praxis and implementation within the treatment paradigm. Moreover, service providers lacked the tools to provide anti-racist services (Shahsiah and Ying Yee 2006). There was also a clear need to redefine mental health to reflect a more holistic definition (Shahsiah and Ying Yee 2006). As noted, racism is a determinant of health (Mikkonen and Raphael 2010), and many organizations strive to implement anti-oppressive standards; however, practices were often conceptual and not always enforced.

\section{Lack of Organizational Support}

Similarly, a lack of organizational support was frequently cited as a barrier for practitioners wishing to provide mental healthcare to Black children and youth. Barriers for practitioners took many forms and included organizational restrictions related to funding requirements and difficulties related to challenging the way that services were delivered. Practitioners faced pushback when implementing innovative programming, and risked marginalization when they challenged current practices to better provide appropriate services (Shahsiah and Ying Yee 2006). Often, this was related to restrictions placed on organizations by funders, whose focus was on evidence-based treatments (Shahsiah and Ying Yee 2006). This focus on evidence-based treatment created tension when practitioners believed those treatments were not the most effective for their clients (Shahsiah and Ying Yee 2006).

Moreover, challenging power structures and the status quo surrounding race and treatment provision was difficult when senior employees were mostly white (Shahsiah and Ying Yee 2006). Organizations often made claims about their values and goals concerning anti-racism and anti-oppression, but changes were often surface-level, and racialized service providers remained tokenized. The surface-level implementation of changes also negatively affected the implementation of assessment tools to track client data (Shahsiah and Ying Yee 2006).

\section{Personal and Community Barriers}

Black youth may avoid or delay seeking care due to cultural stigma (Hasford et al. 2018; Whitley et al. 2017). Mental illness in the Black community is stigmatized (Whitley 2016) and simultaneously unacknowledged by the community (Anucha et al. 2017). Furthermore, in Black communities, mental illness is often attributed to religious interference (Tranulis et al. 2008). Religiosity is helpful in the development of personal schemas surrounding mental illness (Whitley 2016). However, challenges arose when spiritual forces were invoked as the sole cause of illness (Tranulis et al. 2008), and when religious intervention was upheld as the only treatment (Ferrari et al. 2015).

Stigma intersects with the experience of racial discrimination (Shahsiah and Ying Yee 2006), which may lead Black youth to ignore signs and symptoms (Ferrari et al. 2015). Moreover, stigma often led to a lack of discussion, causing youth to look for treatment on their own or delay seeking care, in fear of judgment from their family and community (Anucha et al. 2017; McMurtry and Curling 2008) and to avoid being labeled as "crazy" or "mentally ill" (Lovell and Shahsiah 2006). As a means to self-medicate and shield their illness from family and friends, cannabis was often used as a coping mechanism (Ferrari et al. 2015). Stigma also had implications for treatment adherence (CMHA 2018; Whitley et al. 2017). Stigmatization from mental health providers was considered to be particularly harmful (Ferrari et al. 2018; Shahsiah and Ying Yee 2006) and caused patients to regret seeking treatment (Ferrari et al. 2015; Shahsiah and Ying Yee 2006).

\section{Facilitators to Mental Healthcare}

Family and friends were noted as facilitators to care and as sources of emotional support (Shakya et al. 2010). Moreover, support from family members and friends positively impacted recovery from mental illness (Black Health Alliance 2016). Studies have shown that friends or family initiated between 36 and 56\% of "help-seeking," respectively (Archie et al. 2010; Ferrari et al. 2015). However, this was predicated on family recognizing symptoms and attributing them to mental illness (Archie et al. 2010).

Family involvement also has an impact on treatment adherence, particularly for younger children. For parents of children aged 4-15 with externalizing mental illness symptoms, parental belief in treatment capability, and their ability to manage this behavior impacted treatment engagement and dropout rates (Shanley and Reid 2015). However, this relied upon a family-centered approach and clinicians working to adapt treatments and strategies to include parents' perceptions. In contrast, and with a slightly older population, family involvement may cause clinicians to perceive that patients may be less in need of services, leading to less assertive follow-up, and increasing the likelihood of disengagement (Anderson et al. 2013).

As stated previously, many Black youth have challenges accessing mental health providers. However, having a "connection" to mental health service providers was identified as important to youth (Office of the Provincial Advocate for Children \& Youth 2018) and was considered to be a source of "social support" (Whitley 2016). Lastly, religiosity and religious institutions were mentioned as facilitators to mental healthcare (Whitley 2016), and youth identified religious spaces as being comfortable to seek support from (Shakya 
et al. 2010). Religious competence in treatment may also assist patient recovery (Whitley 2016).

\section{Discussion}

Given the importance of addressing mental health challenges in youth (Lipman and Boyle 2008) and the calls from community organizations for action on mental health in Black Canadian populations (Black Health Alliance 2016; Taylor and Richards 2019), understanding the barriers and facilitators to mental healthcare is necessary. The findings of this review respond to those calls by collecting and summarizing the breadth of knowledge concerning Black youth and mental healthcare access in Canada. Commitment to community is a driving force of this scoping review (Chambers et al. 2014). Thus, sources were drawn from both academic articles and literature created by community organizations. The findings of this review contribute to the gap of current research on this topic.

Barriers were varied and occurred at the systemic, organizational, and interpersonal levels of society. Systemic level barriers included: wait times, poor access to mental practitioners, and geographical and financial barriers to care. Often, when Black youth did access the system, it was because they were involved in the justice system, for reasons both related and unrelated to their mental health, or they were symptomatic enough to warrant outside intervention. In the treatment setting, receiving adequate care that met the needs of Black youth was also difficult. Racism and discrimination from practitioners impacted the experience of seeking care, which was reinforced by care that failed to meet the cultural needs of Black youth. Mental health providers themselves faced constraints when conceptualizing and implementing anti-racist praxis in their work. Interpersonal barriers included stigma and mistrust of the mental healthcare system. Internalized stigma and anticipated stigmatization from their broader community made it less likely that Black youth would seek out mental healthcare and often caused them to hide their mental illness. The stigmatization of Black youth who experience mental illness was compounded if they were further stigmatized by their healthcare providers, which may cause them to regret seeking treatment.

Similar to other systematic reviews on barriers and facilitators to mental health, there were very few references to facilitators to care (Gulliver et al. 2010). Moreover, what emerged in the data focused on personal-level interactions. Support from family, friends, and the broader community, religious organizations, and a good relationship with physicians were all identified as facilitators to mental healthcare. These findings echo those identified by Planey et al. (2019), which found that religion and spirituality, a supportive social network, and positive experiences with caregivers were all contributing factors that facilitated access to care. Planey et al. (2019) also identified referrals from parents, primary care physicians, and teachers as facilitators to care.

Importantly, the juvenile justice system was also identified as a facilitator to care and as the primary referral pathway reported by mothers (Planey et al. 2019). Entry into the mental healthcare system through the justice system was identified as a barrier in this scoping review. However, that may be attritubed to the assertion that entering the mental healthcare system via the justice system was considered a barrier to future mental healthcare-seeking because of negative experiences of this entry pathway (van der Ven et al. 2012; Whitley 2016). Recent reports have identified that Black children and youth in Ontario often rely on the juvenile justice system to receive mental healthcare (Finlay et al. 2019). However, requiring the juvenile penal system to access care highlights the inaccessibility of the current mental healthcare system in Canada. Access to the mental healthcare system through the penal system should not be conflated as a facilitator when the ultimate result is compulsory care and potential alienation from the mental healthcare system.

Many research articles focused on psychosis or psychiatric disorders (Anderson et al. 2013, 2015, 2017; Emerson et al. 2018; Ferrari et al. 2015, 2018; Maraj et al. 2017; Tranulis et al. 2008; van der Ven et al. 2012; Whitley 2016) which can be attributed somewhat to the inclusion of articles associated with a large research study (the African, Caribbean and European (ACE) Pathways project). The ACE Pathways project had four articles which were retrieved in this scoping review. In comparison, few studies focused on anxiety or depression despite being identified as the two most common mental health disorders among youth in Canada (Malla et al. 2018). Thus, the results concerning barriers and facilitators to care may lean heavily towards psychosis, rather than the most common mental health challenges. The heavy focus on psychosis in the articles included in this scoping review highlights the need for further exploration of the barriers and facilitators to care for depression, anxiety, and other forms of mental illness.

There was a significant dearth of articles that explored the barriers and facilitators to mental healthcare for Black youth living in Canada. No articles that met the inclusion criteria focused solely on Black youth, though many articles included Black youth as part of a larger study population, representing a significant gap in available research. Particularly glaring was the lack of articles that focused on facilitators and those which focused on the specific developmental needs of Black children and youth. Furthermore, few peerreviewed literature sources explored the barriers and facilitators to addictions care for Black youth, which may represent a more significant gap in the overall literature and treatment 
focus. Seiler et al. (2011) have noted that there is a need for programs that address addictions. This need would be no different for Black children and youth.

There was also a dearth of research focused on access to mental healthcare for Black youth within Black-led community organizations. Governments have increasingly relied on Black-led community organizations to deliver mental health services (McMurtry and Curling 2008), and because of their immersion within communities, they are uniquely positioned to address mental health concerns. This gap in praxis may be alleviated as community-based participatory research (CBPR) is increasingly utilized in research (Shakya et al. 2010), but for now, the gap between action and knowledge for this population is vast, highlighting an urgent need for focus in this area.

Research conducted in partnership with Black youth or that includes Black youth as a part of the research team was also lacking. Engaging youth in the research process may increase the availability of primary research that further unpacks barriers and facilitators to care. Youth engagement may also provide insight into how current mental healthcare treatments can be adapted or created. Another evident gap was that most research lacked the use of intersectional approaches in identifying barriers and facilitators to care. Few articles explored the needs of Black youth with mental health challenges who identify as LGBTQ+. The overlapping stigmatization of racism, mental illness, and LGBTQ + identity during the formative years requires further exploration.

There was very little insight provided into the facilitators and promoters of mental healthcare, nor was there a strong focus on research from an assets-based perspective. This analysis would be beneficial to highlight successes, especially in the context of work within community organizations. Similarly, the actions needed to define and incorporate concepts related to praxis tangibly were not apparent to practitioners. Concepts were often named, i.e., "anti-racist praxis" or "anti-oppression," but a clear representation of those concepts within the organizational structure, treatments offered, and practice standards was harder to define. Upon review, it was clear that organizations need to critically examine their internal processes, asking, for instance, "what does anti-oppression look like for organizations?" "What does anti-oppression look like for youth workers?" Appraising their internal practices and their effects on treatment provision would alleviate the gap between theory, intention, and practice.

\section{Recommendations for Future Research}

Across all sources, there appears to be a dearth of research that explores the experiences of mental illness and barriers to care for Black youth, especially those who are multiply marginalized (Emerson et al. 2018). There is a need for further peer-reviewed research on barriers to care for Black youth with anxiety, depression, and particularly those who are experiencing challenges with addictions. As well, further research into what interventions are most effective for Black youth and the efficacy of adapting current evidenced-based interventions would address some of the barriers they experience in accessing care, particularly those related to care that is not culturally competent.

Research should query the impact of racism on mental health, both from a qualitative and empirical standpoint (Anderson et al. 2017). Youth perspectives of treatment effectiveness, cultural competence, and the Eurocentric focus of treatment need to be considered (Black Health Alliance 2015; F.A.C.E.S. of Peel Collaborative 2015). Ideally, this research should use a CBPR approach and involve youth throughout the research process.

Community organizations and practitioners would benefit from research that explores and evaluates different approaches to treatment that accounts for experiences of racism and barriers to access; these treatment approaches should also be assessed for feasibility over time (CMHA 2018). The impact of racism and cultural references on the diagnosis of mental illness is of concern. Further evaluation of diagnostic criteria and treatment protocols for Black youth is necessary. Likewise, there is a need for the evaluation of current diagnostic and referral practices of organizations that want to serve Black youth and strategies to avoid adverse pathways to care and wait times. These evaluations would benefit from analysis on the impact of race-based data collection on organizational practice (Adeponle et al. 2012; Anderson et al. 2013; van der Ven et al. 2012).

Black communities have been requesting the collection of race disaggregated data for some time (Black Health Alliance 2015). Although this review did not focus on epidemiological research, the lack of any that pertains to the prevalence of mental illness and which explores which types of mental illnesses most affect this population is a glaring gap in current research concerning Black youth that live in Canada.

\section{Implications}

The articles and gray literature included in this scoping review revealed some implications for mental healthcare in Canada. Foremost, there needs to be a concerted systemic effort to ensure that Black youth are not falling through the cracks of a poorly designed system of care (Lovell and Shahsiah 2006). More funding for the Canadian mental healthcare system is needed, particularly as it relates to Canada's single-payer plan. Two aspects of healthcare have been historically not funded in Canada: prescription drugs and mental healthcare (though both are insured inside of hospitals). 
Recently, the Liberal federal government announced funding for a national pharmacare program (Ballingall 2019). The findings of this article strongly suggest that a similar measure should be taken for mental healthcare.

In noting that a universal mental healthcare system would help to reduce disparities, it is necessary to consider the effects of enforced care and hospitalization. While hospitalization and its merits in mental healthcare treatment are outside the scope of this article, hospitalization was linked to decreased use and dissatisfaction with mental health services (Whitley 2016). Similarly, coordination needs to occur to prevent Black youth with mental illness from interacting with the justice system as a result of that illness, though this will require transformational change within both the mental healthcare and justice systems (Corrigan and Boyle 2003; Finlay et al. 2019).

A universal healthcare system that is expanded to include mental health would address many of the financial barriers to accessing mental healthcare (Archie et al. 2010), but it may be insufficient in addressing all disparities to access. As evidenced by existing racial inequities in accessing care in Canada (Nestel 2012), universality alone will not reduce disparities if it does not consider the effects of racism and the Eurocentric nature of mental healthcare. The findings of this review clearly show that Black children and youth require mental healthcare that is culturally responsive and is affirming of the reality of racism and other forms of oppression (Archie et al. 2010; CMHA 2018; Hasford et al. 2018; Office of the Provincial Advocate for Children \& Youth 2018). For Black youth to be truly served by a mental healthcare system, Afrocentric standards of care must be implemented, and practitioners must be cognizant of the unique needs of Black children and youth to close the "conceptual gap" that currently exists (Shahsiah and Ying Yee 2006).

Funding should be earmarked to aid mental health organizations and researchers to innovate novel mental health treatments and adapt existing evidence-based practices to be culturally competent. There is also a need for more diversity in senior leadership roles in mental health organizations that may be able to allow more flexibility in mental healthcare provision.

\section{Limitations}

Despite best efforts, all studies have limitations. This study was unable to source articles from SOCindex and Google Scholar. Relevant articles may have been missed as a result. Articles written in French were also subject to inclusion, but none were retrieved in our search. Gray literature sources that would have met our inclusion criteria were likely missed; however, steps were taken to mediate this. Namely, sources were reviewed for other potential resources that met inclusion criteria. Due to the dearth in research that focused explicitly on Black youth and access to mental healthcare, the inclusion criteria were expanded to include articles that had Black youth in their sample, even if they were not the target demographic. Thus, findings may be representative of a broader population.

Moreover, few of the articles focused on the developmental aspects of seeking care, an important consideration since Black youth are often perceived as older than they are (Goff et al. 2014) and are socialized differently (Peck et al. 2014). The lack of relevant research is indicative of the broader limitations of research concerning access to mental healthcare and Black children and youth. However, the findings represent the current state of research concerning the experiences of Black children and youth in Canada to the best of their ability.

Defining race was challenging. The term "racialized" or countries of origin were often used in place of race or ethnicity. Assumptions concerning race were often required to identify whether a gray literature document met the inclusion criteria. Moreover, though necessary, the reduction of the African diasporic populations to simply "Black" in this scoping review has implications. Much work has been done to affirm the diverse diasporic cultures and socio-political histories of African, Caribbean and Black people in Canada (Fante-Coleman et al. 2019; Maticka-Tyndale et al. 2016) and the authors are wary of oversimplifying and essentializing the "complex, blurred and sometimes blended" experiences and realities of this population (Chambers et al. 2014). However, the defining of populations is somewhat constrained by the methodology of scoping reviews (Chambers et al. 2014). The findings were shared at community outreach sessions and with community members-at-large, in addition to data-checking sessions with stakeholders of the Pathways to Care project, to ensure results reflected reality.

\section{Conclusion}

Much remains unknown about the barriers and facilitators to accessing mental healthcare for Black children and youth; Thus, the purpose of this scoping review was to address gaps in extant research on this topic. A review was conducted on sources that focused on Black youth in the Canadian context. The review yielded 33 sources. Many barriers to care were identified, including barriers at the systemic level (i.e., wait times, poor access to mental health professionals, geographical and financial barriers) and adverse pathways to care, including interactions with imposed services and hospitalization. As well, certain aspects of receiving care from practitioners posed a challenge for Black children and youth. Particularly, racism and discrimination from practitioners caring for Black youth and organizational challenges for practitioners who wanted to innovate ways of providing 
care made addressing mental health in Black youth people more difficult. Lastly, personal and community barriers related to cultural stigma also hindered access to care. While there were fewer facilitators, family and community, and a connection with mental health providers were considered to aid access. The implications of these findings highlight that despite a universal healthcare system, many challenges remain for Black children and youth accessing mental healthcare. The findings suggest that the current organization of the healthcare system in Canada is detrimental to youth. Many of these challenges further implicate practitioners and organizations and highlight the importance of adapting to the needs of Black children and youth integrally. Research that focuses on Black youth that is rooted in community-based participatory research approaches is imperative. Moreover, further research should explore facilitators, developmental needs, and intersecting identities in the context of mental illness. By synthesizing and summarizing existing research, this article answers a call from the Black community in Canada and provides a basis for further research that concerns this population.

Acknowledgements The authors would like to thank the stakeholder organizations of Pathways to Care: Black Health Alliance, The Centre for Addictions and Mental Health (CAMH), East Metro Youth Services, TAIBU Community Health Centre and the Wellesley Institute. The authors would also like to thank Chevy Eugene for their support.

Author's Contributions TFC conceived of the study, participated in its design and the interpretation of data and the writing of the manuscript. TFC has read and approved the final manuscript. FJB conceived of the study, interpreted data and helped draft the manuscript. FJB has read and approved the final manuscript.

Funding Public Health Agency of Canada (1920-HQ-000056) and the Ontario Trillium Foundation's Youth Opportunity Fund (\#12102) provided funding for this scoping review.

\section{Compliance with Ethical Standards}

Conflicts of interest Tiyondah Fante-Coleman and Fatimah JacksonBest are employed by the Pathways to Care Project. Black Health Alliance is the primary stakeholder of the Pathways to Care project.

Research Involving Human and Animal Participants This article does not contain any studies with human or animal subjects performed by any of the authors.

Informed Consent For this type of study, formal consent is not required.

Open Access This article is licensed under a Creative Commons Attribution 4.0 International License, which permits use, sharing, adaptation, distribution and reproduction in any medium or format, as long as you give appropriate credit to the original author(s) and the source, provide a link to the Creative Commons licence, and indicate if changes were made. The images or other third party material in this article are included in the article's Creative Commons licence, unless indicated otherwise in a credit line to the material. If material is not included in the article's Creative Commons licence and your intended use is not permitted by statutory regulation or exceeds the permitted use, you will need to obtain permission directly from the copyright holder. To view a copy of this licence, visit http://creativecommons.org/licenses/by/4.0/.

\section{References}

Adeponle, A. B., Thombs, B. D., Groleau, D., Jarvis, E., \& Kirmayer, L. J. (2012). Using the cultural formulation to resolve uncertainty in diagnoses of psychosis among ethnoculturally diverse patients. Psychiatric Services, 63(2), 147-153. https://doi.org/10.1176/ appi.ps.201100280.

Adjei, P. B., \& Minka, E. (2018). Black parents ask for a second look: Parenting under 'White' child protection rules in Canada. Children and Youth Services Review, 94, 511-524. https://doi. org/10.1016/j.childyouth.2018.08.030.

Alexander, D. (2018). Clinical practice framework for working with clients of African descent.

Anderson, K. (2015). Pathways to first-episode care for psychosis in African-, Caribbean-, and European-origin groups in Ontario. Canadian Journal of Psychiatry, 60(5), 223-231. https://doi. org/10.1177/070674371506000504.

Anderson, K. K., Fuhrer, R., Schmitz, N., \& Malla, A. K. (2013). Determinants of negative pathways to care and their impact on service disengagement in first-episode psychosis. Social Psychiatry and Psychiatric Epidemiology, 48(1), 125-136. https://doi. org/10.1007/s00127-012-0571-0.

Anderson, K. K., Cheng, J., Susser, E., McKenzie, K. J., \& Kurdyak, P. (2015). Incidence of psychotic disorders among first-generation immigrants and refugees in Ontario. CMAJ, 187(9), 279-286. https://doi.org/10.1503/cmaj.141420.

Anderson, K. K., McKenzie, K. J., \& Kurdyak, P. (2017). Examining the impact of migrant status on ethnic differences in mental health service use preceding a first diagnosis of schizophrenia. Social Psychiatry and Psychiatric Epidemiology: The International Journal for Research in Social and Genetic Epidemiology and Mental Health Services, 52(8), 949-961. https://doi.org/10.1007/ s00127-017-1403-z.

Anucha, U., Srikanthan, S., Siad-Togane, R., \& Galabuzi, G. E. (2017). Doing right together for black youth: What we learned from the community engagement sessions for the Ontario Black youth action plan. Toronto: Youth Research and Evaluation eXchange.

Archie, S., Akhtar-Danesh, N., Norman, R., Malla, A., Roy, P., \& Zipursky, R. B. (2010). Ethnic diversity and pathways to care for a first episode of psychosis in Ontario. Schizophrenia Bulletin, 36(4), 688-701. https://doi.org/10.1093/schbul/sbn137.

Arday, J. (2018). Understanding mental health: What are the issues for black and ethnic minority students at University? Social Sciences. https://doi.org/10.3390/socsci7100196.

Arksey, H., \& O’Malley, L. (2005). Scoping studies: Towards a methodological framework. International Journal of Social Research Methodology, 8(1), 19-32. https://doi.org/10.1080/1364557032 000119616.

Ballingall, A. (2019). Justin Trudeau slams Doug Ford as he lays out 'down payment' for pharmacare and better health services. Toronto Star. Retrieved September 23, 2019 from https://www. thestar.com/politics/federal/2019/09/23/justin-trudeau-slams -doug-ford-as-he-lays-out-down-payment-for-pharmacare-andbetter-health-services.html

Black Health Alliance. (2015). A sound mind: Mental health in the Black community. Toronto, ON: Black Health Alliance. 
Black Health Alliance. (2016). A sound mind II: Mental health and youth. Toronto, ON: Black Health Alliance.

Braun, V., \& Clarke, V. (2006). Using thematic analysis in psychology. Qualitative Research in Psychology, 3(2), 77-101. https:// doi.org/10.1191/1478088706qp063oa.

Canadian Mental Health Association. (2018). Bringing mental health into balance: A mental health parity act. Retrieved August 26, 2019, from www.cmha.ca

Chambers, L. A., Wilson, M. G., Rueda, S., Gogolishvili, D., Shi, M. Q., Rourke, S. B., et al. (2014). Evidence informing the intersection of HIV, aging and health: A scoping review. AIDS and Behavior, 18(4), 661-675. https://doi.org/10.1007/s10461-013-0627-5.

Chiu, M. (2017). Ethnic differences in mental health and race-based data collection. Healthcare Quarterly. https://doi.org/10.12927/ hcq.2017.25296.

Commander, M. J., Cochrane, R., Sashidharan, S. P., Akilu, F., \& Wildsmith, E. (1999). Mental health care for Asian, black and white patients with non-affective psychoses: Pathways to the psychiatric hospital, in-patient and after-care. Social Psychiatry and Psychiatric Epidemiology, 34(9), 484-491. https://doi.org/10.1007/s0012 70050224.

Corrigan, P. W., \& Boyle, M. G. (2003). What works for mental health system change: Evolution or revolution? Administration and Policy in Mental Health, 30(5), 379-395. https://doi. org/10.1023/A:1024619913592.

Cummings, J. R., \& Druss, B. G. (2011). Racial/ethnic differences in mental health service use among adolescents with major depression. Journal of the American Academy of Child and Adolescent Psychiatry, 50(2), 160-170. https://doi.org/10.1016/j. jaac.2010.11.004.

Dufresne, Y., Jeram, S., \& Pelletier, A. (2014). The true north strong and free healthcare? Nationalism and attitudes towards private healthcare options in Canada. Canadian Journal of Political Science, 47(3), 569-595.

Emerson, S. D., Minh, A., \& Guhn, M. (2018). Ethnic density of regions and psychiatric disorders among ethnic minority individuals. International Journal of Social Psychiatry, 64(2), 130-144. https://doi.org/10.1177/0020764017747909.

F.A.C.E.S. of Peel Collaborative. (2015). The black community in peel. Peel Region: Region of Peel and United Way.

Fante-Coleman, T., Wilson, C. L., Marcotte, A. A., McKie, R., Travers, R., \& Furman, E. (2019). Influences of sexual behaviors and vulnerability to HIV/AIDS among heterosexual ACB youth living in Windsor, Ontario. Journal of Social and Personal Relationships, 36(11-12), 3515-3536. https://doi.org/10.1177/02654 07519826350.

Ferrari, M., Flora, N., Anderson, K. K., Tuck, A., Archie, S., Kidd, S., et al. (2015). The African, Caribbean And European (ACE) pathways to care study: A qualitative exploration of similarities and differences between African-origin, Caribbean-origin and European-origin groups in pathways to care for psychosis. British Medical Journal Open. https://doi.org/10.1136/bmjop en-2014-006562.

Ferrari, M., Flora, N., Anderson, K. K., Haughton, A., Tuck, A., Archie, S., et al. (2018). Gender differences in pathways to care for early psychosis. Early Intervention in Psychiatry, 12(3), 355-361. https://doi.org/10.1111/eip.12324.

Finlay, J., Scully, B., Farrel, T., Dicks, P., \& Salerno, J. (2019). Cross-over youth project: Navigating Quicksand. Toronto, ON: Ryerson University.

Goff, P. A., Jackson, M. C., Di Leone, B. A. L., Culotta, C. M., \& DiTomasso, N. A. (2014). The essence of innocence: Consequences of dehumanizing black children. Journal of Personality and Social Psychology, 106(4), 526-545. https://doi.org/10.1037/a0035663.

Grant, K. (2017). Canada ranks third-last in study of health care in 11 rich countries-The Globe and Mail. The Globe and Mail.
Gulliver, A., Griffiths, K. M., \& Christensen, H. (2010). Perceived barriers and facilitators to mental health help-seeking in young people: A systematic review. BMC Psychiatry, 10(1), 113. https ://doi.org/10.1186/1471-244X-10-113.

Haner, D., \& Pepler, D. (2016). "Live Chat" Clients at Kids Help Phone: Individual Characteristics and Problem Topics. Journal of the Canadian Academy of Child and Adolescent Psychiatry, 25(3), 138-144.

Hasford, J., Amponsah, P., \& Hylton, T. (2018). Anti-racist praxis with street-involved African Canadian youth. In S. Kidd, N. Slesnick, T. Frederick, J. Karabanow, \& S. Gaetz (Eds.), Mental health \& addiction interventions for youth experiencing homelessness (pp. 125-137). Toronto, ON: Canadian Observatory on Homelessness Press.

Khenti, A. A. (2013). Homicide among young black men in Toronto: An unrecognized public health crisis? Canadian Journal of Public Health, 104(1), e12-e14. https://doi.org/10.1007/bf03405647.

Lalonde, R. N., Jones, J. M., \& Stroink, M. L. (2008). Racial identity, racial attitudes, and race socialization among Black Canadian parents. Canadian Journal of Behavioural Science, 40(3), 129-139. https://doi.org/10.1037/0008-400X.40.3.129.

Levac, D., Colquhoun, H., \& O’Brien, K. K. (2010). Scoping studies: Advancing the methodology. Implementation Science, 5(1), 5-69. https://doi.org/10.1186/1748-5908-5.

Lipman, E. L., \& Boyle, M. H. (2008). Linking poverty and mental health. Hamilton: CHEO.

Lovell, A., \& Shahsiah, S. (2006). Mental well-being and substance use among youth of colour. Toronto, $\mathrm{ON}$ : Across Boundaries.

MacDonald, K., Fainman-Adelman, N., Anderson, K. K., \& Iyer, S. N. (2018). Pathways to mental health services for young people: A systematic review. Social Psychiatry and Psychiatric Epidemiology. https://doi.org/10.1007/s00127-018-1578-y.

Malla, A., Shah, J., Iyer, S., Boksa, P., Joober, R., Andersson, ... Fuhrer, R. (2018). Youth Mental Health Should Be a Top Priority for Health Care in Canada. Canadian Journal of Psychiatry, 63(4), 216-222. https://doi.org/10.1177/0706743718758968

Maraj, A., Anderson, K. K., Flora, N., Ferrari, M., Archie, S., McKenzie, K. J., ... Tuck, A. (2017). Symptom profiles and explanatory models of first-episode psychosis in African-, Caribbean- and European-origin groups in Ontario. Early Intervention in Psychiatry, 11(2), 165-170. https://doi.org/10.1111/ eip. 12272

Martin, D., Miller, A. P., Quesnel-Vallée, A., Caron, N. R., Vissandjée, B., \& Marchildon, G. P. (2018). Canada's universal health-care system: Achieving its potential. The Lancet, 391, 1718-1735. https://doi.org/10.1016/S0140-6736(18)30181-8.

Maticka-Tyndale, E., Kerr, J., \& Mihan, R. (2016). A profile of the sexual experiences of African, Caribbean and Black Canadian youth in the context of Canadian youth sexuality. Canadian Journal of Human Sexuality, 25(1), 41-52. https://doi. org/10.3138/cjhs.251-A1.

McMurtry, R., \& Curling, A. (2008). The review of the roots of youth violence: Findings, analysis and conclusion. Toronto, ON: Queen's Printer for Ontario.

Merikangas, K. R., He, J. P., Burstein, M., Swendsen, J., Avenevoli, S., Case, ...Olfson, M. (2011). Service utilization for lifetime mental disorders in U.S. adolescents: Results of the national comorbidity survey Adolescent supplement (NCS-A). Journal of the American Academy of Child and Adolescent Psychiatry, 50(1), 32-45. https://doi.org/10.1016/j.jaac.2010.10.006

Mikkonen, J., \& Raphael, D. (2010). Social determinants of health: The Canadian facts. Toronto: York University School of Health Policy and Management. Retrieved June 15, 2017, from http:// www.thecanadianfacts.org/the_canadian_facts.pdf.

Nestel, S. (2012). Colour Coded Health Care. Wellesley Institute. Toronto, ON. Retrieved June 25, 2017, from https://www.welle 
sleyinstitute.com/wp-content/uploads/2012/02/Colour-Coded -Health-Care-Sheryl-Nestel.pdf

Office of the Provincial Advocate for Children \& Youth. (2018). HairStory: Rooted. Retrieved March 27, 2019, from https:// static1.squarespace.com/static/5c77f078a9ab955d57bca3ab/ t/5c9187e7e79c7001701774ab/1553041387661/HS_ROOTE D-A+Firm+Foundation+for+Black+Youth.pdf.

Ontario Ministry of Children and Youth Services. (2016). Because young people matter: Report of the residential services review panel. Retrieved August 14, 2019, from https://www.children. gov.on.ca/htdocs/English/documents/childrensaid/residentia 1-services-review-panel-report-feb2016.pdf

Pahwa, P., Karunanayake, C. P., McCrosky, J., \& Thorpe, L. (2012). Longitudinal trends in mental health among ethnic groups in Canada. Chronic Diseases and Injuries in Canada, 32(3), 164-176.

Paradies, Y. (2006). A Systemic Review of Empirical Research on Self-Reported Racism and Health. International Journal of Epidemiology, 35(4), 888-901.

Patel, A. (2015). Stigma and Silence: Black Canadians and the fight for mental health awareness. Huffington Post Canada.

Peck, S. C., Brodish, A. B., Malanchuk, O., Banerjee, M., \& Eccles, J. S. (2014). Racial/ethnic socialization and identity development in black families: The role of parent and youth reports. Developmental Psychology, 50(7), 1897-1909. https://doi. org/10.1037/a0036800.

Planey, A. M., Smith, S. M. N., Moore, S., \& Walker, T. D. (2019). Barriers and facilitators to mental health help-seeking among African American youth and their families: A systematic review study. Children and Youth Services Review, 101, 190-200. https ://doi.org/10.1016/j.childyouth.2019.04.001.

Rodney, P., \& Copeland, E. (2009). The health status of Black Canadians: Do aggregated racial and ethnic variables hide health disparities? Journal of Health Care for the Poor and Underserved, 20(3), 817-823. https://doi.org/10.1353/hpu.0.0179.

Rousseau, C., Hassan, G., Measham, T., \& Lashley, M. (2008). Prevalence and correlates of conduct disorder and problem behavior in Caribbean and Filipino immigrant adolescents. European Child \& Adolescent Psychiatry, 17(5), 264-273. https://doi. org/10.1007/s00787-007-0640-1.

Seiler, G., Shamonda, F., \& Thompson, K. (2011). Race, risk, and resilience: Implications for community based practices in the Black community of Montreal. Montreal, QC: DESTA Black Youth Network. Retrieved August 21, 2019, from https://www. destabyn.org/wordpress/wp-content/uploads/Race-Risk-andResiliency-Research-complete.pdf

Shahsiah, S., \& Ying Yee, J. (2006). Striving for best practices and equitable mental health care access for racialised communities in Toronto. Toronto, ON: Access Alliance Multicultural Community Health Centre and Across Boundaries.

Shakya, Y. B., Khanlou, N., \& Gonsalves, T. (2010). Determinants of mental health for newcomer youth: Policy and service implications. Toronto, ON: Access Alliance. Retrieved August 22, 2019, from https://accessalliance.ca/wp-content/ uploads/2018/06/Determinants_of_Mental_Health_for_Newco mer_YouthCdn_Issues.pdf

Shanley, D. C., \& Reid, G. J. (2015). The impact of parents' illness representations on treatment acceptability for child mental health problems. Journal of Emotional and Behavioral Disorders, 23(2), 115-127. https://doi.org/10.1177/1063426614 532832 .

Statistics Canada. (2016). Census Profile, 2016. Ottawa. Retrieved November 22, 2019, from https://www12.statc an.gc.ca/census-recensement/2016/dp-pd/prof/details/page. cfm ?Lang $=$ E $\&$ Geo $1=$ PR $\&$ Code $1=01 \&$ Geo $2=$ PR \&Code 2 $=01 \&$ Data $=$ Count $\&$ SearchText $=$ canada $\&$ SearchType $=$ Begin $\mathrm{s} \&$ SearchPR $=01 \& \mathrm{~B} 1=\mathrm{All} \& \mathrm{TABID}=1$

Taylor, D., \& Richards, D. (2019). Triple jeopardy: Complexities of racism, sexism, and ageism on the experiences of mental health stigma among young Canadian Black Women of Caribbean descent. Frontiers in Sociology. https://doi.org/10.3389/ fsoc.2019.00043.

Thomson, M. S., Chaze, F., George, U., \& Guruge, S. (2015). Improving immigrant populations' access to mental health services in Canada: A review of barriers and recommendations. Journal of Immigrant and Minority Health, 17(6), 1895-1905. https://doi.org/10.1007/s10903-015-0175-3.

Tranulis, C., Corin, E., \& Kirmayer, L. J. (2008). Insight and psychosis: Comparing the perspectives of patient, entourage and clinician. International Journal of Social Psychiatry, 54(3), 225-241. https://doi.org/10.1177/0020764008088860.

van der Ven, E., Bourque, F., Joober, R., Selten, J. P., \& Malla, A. K. (2012). Comparing the clinical presentation of first-episode psychosis across different migrant and ethnic minority groups in Montreal, Quebec. Canadian Journal of Psychiatry, 57(5), 300-308. https://doi.org/10.1177/070674371205700505.

Whitley, R. (2012). Religious competence as cultural competence. Transcultural Psychiatry, 49(2), 245-260. https://doi. org/10.1177/1363461512439088.

Whitley, R. (2016). Ethno-racial variation in recovery from severe mental illness. The Canadian Journal of Psychiatry, 61(6), 340-347. https://doi.org/10.1177/0706743716643740.

Whitley, R., Wang, J., Fleury, M.-J. J., Liu, A., \& Caron, J. (2017). Mental health status, health care utilisation, and service satisfaction among immigrants in Montreal: An epidemiological comparison. Canadian Journal of Psychiatry, 62(8), 570-579. https://doi. org/10.1177/0706743716677724.

Williams, D. R., González, H. M., Neighbors, H., Nesse, R., Abelson, J. M., Sweetman, J., et al. (2007). Prevalence and distribution of major depressive disorder in African Americans, Caribbean blacks, and non-Hispanic whites: Results from the National Survey of American Life. Archives of General Psychiatry, 64(3), 305-315. https://doi.org/10.1001/archpsyc.64.3.305.

Woodgate, R. L., \& Busolo, D. S. (2018). Above chaos, quest, and restitution: narrative experiences of African immigrant youth's settlement in Canada. BMC Public Health, 18(1), 333. https://doi. org/10.1186/s12889-018-5239-6.

Publisher's Note Springer Nature remains neutral with regard to jurisdictional claims in published maps and institutional affiliations. 